\title{
PERFIL MICROBIOLÓGICO E QUÍMICO DE EXTRATOS PADRONIZADOS DE INGA
}

MARGINATA

\section{MICROBIOLOGICAL AND CHEMICAL FINGERPRINT OF STANDARDIZED EXTRACTS OF INGA MARGINATA}

\author{
Marcel T. MORIWAKI'; Gerson NAKAZATO2; Renata K. T. KOBAYASHI'; Alexandre \\ T. MOREY2; Terezinha J. FARIA3; Audrey A. S. G. LONNI ${ }^{4 *}$
}

1 - Graduando de Farmácia, departamento de ciências farmacêuticas, Universidade Estadual de Londrina, Londrina - PR, Brasil.

2 - Departamento de Microbiologia, Universidade Estadual de Londrina, Londrina - PR, Brasil.

3 - Departamento de Química, Universidade Estadual de Londrina, Londrina - PR, Brasil.

4 - Departamento de Ciências Farmacêuticas, Universidade Estadual de Londrina, Londrina - PR, Brasil.

*Autor para correspondência: E-mail: audreylonni@uol.com.br

\section{RESUMO:}

Doenças infecciosas vêm apresentando crescente mortalidade no mundo, para o tratamento destas enfermidades as plantas se destacam por apresentar diversas espécies que atuam como agentes terapêuticos. Inga marginata Willd está classificado entre as dez espécies de plantas mais importantes da região do médio Tibagi do estado do Paraná. De acordo com alguns autores a atividade antimicrobiana de folhas de Inga marginata revela um potencial uso desta planta frente a alguns patógenos humanos. Mas devido à carência de uma avaliação mais precisa da espécie, surgiu à necessidade de um estudo, visando elucidar algumas propriedades químicas e microbiológicas desta planta. Com este trabalho foi possível obter informações sobre as melhores condições de extração dos compostos de interesse da planta por meio de um modelo de misturas, determinar o teor de compostos fenólicos totais e avaliar a atividade antimicrobiana da planta contra bacterias Gram positivas e negativas como S. aureus, S. epidermidis, E. coli e P. aeruginosa, como também para fungos como Candida albicans, $\mathrm{C}$. tropicalis and C. glabrata. Com os resultados se constatou que os extratos 1 e 2 extraídos com somente água e etanol, respectivamente, demonstraram efeito bacteriostático contra os microorganismos testados. Isso demonstra uma potencial atividade antibacteriana dos extratos, podendo ser aplicados em formulações farmacêuticas com finalidade antisséptica. Desta forma, a espécie pesquisada pode ser uma alternativa promissora para substituição dos antissépticos usuais de origem sintética por antissépticos de origem natural com menor toxicidade para o ser humano e meio ambiente.

Palavras-chave: Inga marginata, atividade antimicrobiana; folhas.

\section{ABSTRACT:}

Infectious diseases for the treatment of diseases like plants stand out because they present all the species that act as therapeutic agents. Inga marginata Willd is classified as the ten most important plant species of the region of the middle Tibagi of the state of Paraná. According to some authors an antimicrobial activity of leaves of Inga marginata reveals a potential use of this plant against some human pathogens. But due to the lack of a more 
accurate evaluation of the species, the need for a study, in order to elucidate some chemical and microbiological of this plant. With this work, it was possible to obtain information about the best extraction conditions of compounds of plant interest by means of a model of mixtures, to determine the total phenolic compounds content and to evaluate an antimicrobial activity of the plant against Gram positive and negative bacteria such as S. aureus, S. epidermidis, E. coli and P. aeruginosa, as well as for fungi such as Candida albicans, C. tropicalis and C. glabrata. With the results obtained for extracts 1 and 2 extracted with only water and ethanol, respectively, they demonstrated a bacteriostatic effect against the microorganisms tested. This demonstrates a potential antibacterial activity of the extracts, and can be applied in pharmaceutical formulations with antiseptic purpose. Thus, a researched species may be a promising alternative for the substitution of antiseptics, it is of synthetic origin by antiseptics of natural origin with less toxicity to humans and the environment.

Keywords: Inga marginata; antimicrobial activity; leaf.

\section{INTRODUÇÃO}

O Brasil é o país com a maior diversidade biológica do planeta, com grande potencial no campo das pesquisas de compostos para fins terapêuticos obtidos de plantas. Compostos que além ser utilizados na profilaxia e cura de doenças, traz benefícios para sociedade em geral, como para a indústria, consumidores e meio ambiente. (PIMENTEL et al., 2015).

O número de infecções causadas por bactérias patogênicas, principalmente multirresistentes (MR), tem crescido nos últimos anos e atualmente é considerada umas das principais causas de morbidade e mortalidade no planeta. Microrganismos cada vez mais resistêntes pelo uso demasiado de antimicrobianos para controle de infecções. controle de pacientes infectados é um grande desafio tendo em vista os antimicrobianos disponíveis no mercado. Este problema preocupa o sistema de saúde público do Brasil e do mundo. (CLSI, 2015).

O uso de antimicrobianos para controle de infecções induz a evolução dos microrganismos cada vez mais resistentes aos mesmos, como é o caso dos microrganismos multirresistentes (MR). O Centers for Disease Control and Prevention (CDC/NHSN, 2014) define os MR predominantemente como bactérias que são resistentes a três ou mais classes de agentes antimicrobianos, dentro deste critério incluímos os Staphylococcus aureus resistentes a meticilina (MRSA), e produtores de betalactamases e carbapenemases (KPC- Klebsiella enterobacter e Citrobacter produtores de carbapenemases). (TRABULSI; ALTERTHUM, 2004; NYILASI et al., 2010).

Uma possível nova alternativa para o combate destes microrganismos é o uso do Inga marginata Willd, planta conhecida popularmente como ingá-mirim ou ingá-feijão. A espécie 
I. marginata é nativa da Mata Atlântica e considerada de grande importância para a região do Médio Tibagi do estado do Paraná, por contribuir com a manutenção do equilíbrio ecológico e a ocupação de áreas degradadas. Esta espécie, pertence à família das Fabaceae que possui cerca de 40 gêneros e 350 a 400 espécies distribuídas na América tropical e subtropical. A árvore possui cerca de 5 a $20 \mathrm{~m}$ de altura, sendo amplamente distribuída no território brasileiro e em quase toda América Sul ${ }^{12}$. No Brasil, distribui-se do Amapá ao Rio Grande do Sul, com uma ampla faixa de adaptação ecológica e altitudinal, porém, com maior prevalência em matas fluviais. Os frutos do Ingá são comestíveis e de agradável sabor, sendo utilizados na fabricação de refrigerantes. (POSSETTE; RODRIGUES, 2010; GUIMARÃES; MOMESSO; PUPO 2010; LORENZI, 2002).

Na medicina popular, o fruto do Ingá é indicado no tratamento de úlceras. O decocto da casca é adstringente e hemostático. As raízes são indicadas para o tratamento de disenteria e diarréia crônica. (ÁLVAREZ et al., 1998). Algumas espécies de Ingá apresentam efeito antidiarréico, anti-inflamatório e antioxidante. (LIMA, 2015). Alguns estudos relatam a presença de compostos como saponinas, taninos, fitoesteróis e triterpenos no córtex da planta com atividade antitumoral. (LIMA 2015). As saponinas do extrato etanólico presentes no córtex da I. marginata foram ativos contra fungos Mucor sp., Pithiumdebaryanum e Candida albicans. Apesar das propriedades relatadas, a espécie $I$. marginata ainda é pouco estudada. (ÁLVAREZ et al., 1998).

Devido à necessidade de mais pesquisas em relação à composição química e atividade biológica, este trabalho foi elaborado com o objetivo de avaliar as melhores condições de extração, bem como, avaliar a atividade antimicrobiana e as propriedades químicas de folhas de I. marginata.

\section{MATERIAL E MÉTODOS}

\subsection{Obtenção da matéria-prima}

As folhas de Inga marginata Wiild foram coletadas nas proximidades da Universidade Estadual de Londrina, na cidade de Londrina, estado do Paraná, 2319'31.09"S 51¹1'59.92"W. O material passou por uma triagem, sendo escolhidas as folhas em melhores condições, livres de contaminação e decomposição. Em seguida, foram limpas e secas à temperatura ambiente, longe da luz e umidade, durante sete dias.

A identificação botânica da espécie foi realizada pela Profa. Dra. Ana Odete Santos 
Vieira e uma exsicata da planta encontra-se depositada no Herbário da UEL sob o número 40.918. A exsicata foi elaborada segundo as técnicas tradicionais. (DI STASI, 1996).

\subsection{Preparo dos extratos brutos}

As folhas secas de l. marginata foram submetidas à extração por meio de turbólise, na concentração de 10\% (m/v), utilizando três solventes: água, etanol e diclorometano. Em seguida, a mistura foi filtrada, concentrada sob pressão reduzida em um evaporador rotativo $\left(40{ }^{\circ} \mathrm{C} \pm 2{ }^{\circ} \mathrm{C}\right)$ e depois liofilizada. O sistema extrator foi escolhido seguindo um planejamento experimental do tipo simplex-centroide com três componentes representado por triângulo equilátero (BARROS NETO; SCARMINIO; BRUNS, 2002), conforme figura 1 e tabela 1. Os pontos 1, 2 e 3 (vértices)2 da figura 1 correspondem aos solventes puros: (1) água, (2) etanol e (3) diclorometano. Os pontos 4, 5 e 6 (arestas), foram obtidos por misturas de volumes iguais dos solventes água-etanol, etanol-diclorometano, diclorometano-água, respectivamente. Os demais pontos apresentam a seguinte composição: (7) como ponto central obtido pela mistura de volumes iguais dos solventes: água, etanol e diclorometano, (8) 68\% água,16\% etanol e 16\% diclorometano, (9) 16\% água, 68\% etanol e 16\% diclorometano 16\% e (10) 68\% diclorometano, 16\% água e 16\% etanol, totalizando 10 extratos brutos de folhas de I. marginata, denominados de EBIF seguido da numeração correspondente ao extrato.

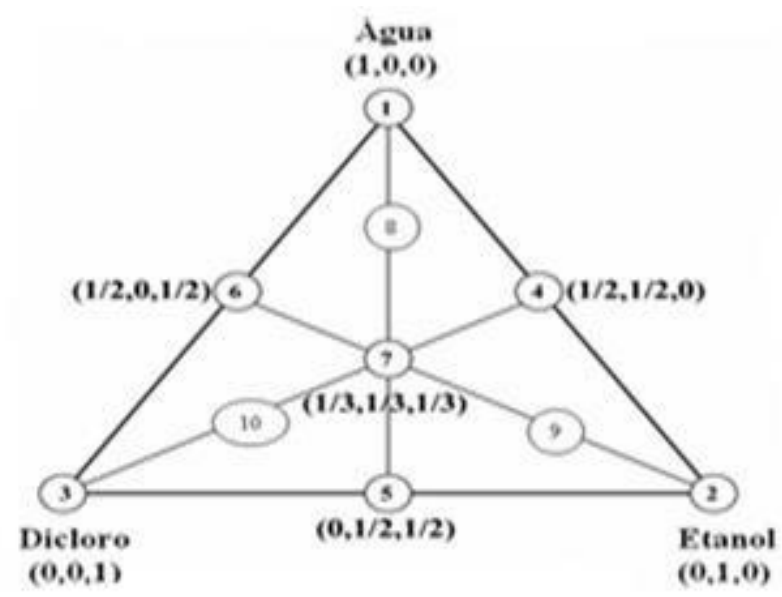

Figura 1. Modelo Simplex-centroide com 3 componentes usados para otimizar a composição do veículo extrator. 


\subsection{Determinação do teor de fenólicos totais e taninos totais}

A partir do rendimento, calculou-se o valor pesado de cada extrato utilizado na análise. As amostras foram diluídas com água destilada, completando o volume para 250 $\mathrm{ml}$. A partir da solução concentrada, foram transferidos $4 \mathrm{~mL}$ para um balão volumétrico de $25 \mathrm{ml}$, onde foram adicionados $1 \mathrm{~mL}$ de reagente Folin-Ciocalteu $2 \mathrm{~N}$ solução de ácido fosfotúngstico R (Sigma-Aldrich, EUA), $10 \mathrm{~mL}$ de água destilada e completando o volume final de $25 \mathrm{ml}$, com uma solução de carbonato de sódio (29\%). Após 30 minutos das amostras deixadas ao abrigo da luz, verificou-se a absorvância a um comprimento de onda de $760 \mathrm{~nm}$, empregando-se a água para calibrar o equipamento (Shimadzu UV/VIS PC1650). O teor de taninos totais (TT) foi calculado de acordo com a equação descrita na Farmacopéia Européia (European Pharmacopoeia, 2007) e foi expresso em porcentagem de pirogalol, determinado de acordo com a equação 1:

$$
\mathrm{TT}(\%)=\frac{6,25 \times \mathrm{A} 1 \times \mathrm{m} 2}{\mathrm{~m} 1 \times \mathrm{A} 2}
$$

Equação 1: Determinação do teor de taninos totais, onde $\mathrm{m} 1$ é a massa da amostra e $\mathrm{m} 2$ é a massa do pirogalol em gramas. A1 e A2 são as absorbâncias da amostra e pirogalol, respectivamente. Fator de diluição ajustado conforme a diluição realizada (4:25).

\subsection{Atividade antimicrobiana Teste Disco-Difusão em Ágar}

Avaliou-se a atividade antibacteriana de EBIF pelo método de Disco-Difusão em Ágar Mueller Hinton (Difcoß), segundo o protocolo do Clinical Laboratory Standard Institute (CLSI, 2015). Foram impregnados $10 \mu \mathrm{L}$ dos compostos contendo $500 \mu \mathrm{g}$ em cada disco de papel esterilizado e testados contra as espécies bacterianas: Staphylococcus aureus (ATCC 25923), Staphylococcus epidermidis (ATCC IE4248), Escherichia coli (ATCC 25922) e Pseudomonas aeruginosa (ATCC 27853). Diâmetros (em mm) dos halos de inibição foram mensurados e comparados entre si e com os antimicrobianos convencionais da tabela do CLSI (2015). 


\subsection{Teste Time-Kill}

Para a realização do experimento foram utilizadas cepas de Staphylococcus aureus (ATCC 25923 e 29213), Staphylococcus aureus meticilina resistente (MRSA) (BEC9393) e Staphylococcus epidermidis (ATCC IE4248). O inóculo bacteriano foi padronizado com a escala 0,5 de MacFarland (que corresponde a aproximadamente 1,5 x108 UFC/mL), e posteriormente diluído 1:100 em caldo Mueller Hinton (MH) (Difco®), obtendo-se uma suspensão de $1,5 \times 106$ UFC/mL, a qual foi utilizada nos ensaios. A concentração inicial dos extratos testados foi de $1000 \mu \mathrm{g} / \mathrm{mL}$.

Alíquotas das amostras testadas foram diluídas e plaqueadas em diferentes tempos de incubação $(0,2,4,7,10$ e 24h). Após este tempo, as unidades formadoras de colônias (UFC) foram contadas e o resultado foi expresso em UFC.

Os dados foram inseridos em uma curva de crescimento e morte bacteriana (UFC/mL) em função do tempo (horas), conforme mostra a figura 2, para a análise da cinética de ação dos compostos sobre a bactéria testada.

\subsection{Atividade antifúngica}

Para a atividade antifúngica foi realizada a determinação da Concentração Inibitória Mínima (CIM) de EBIF, segundo CLSI (2015). Foram utilizadas as cepas de C. albicans, C. tropicalis e C. glabrata. O experimento foi realizado em microplaca de poliestireno com 96 poços com fundo chato.

Foi utilizado o meio Roswell Park Memorial Institute médium (RPMI), com tampão 3-morpholinopropane-1-sulfonic acid (MOPS) preparado e filtrado em membrana. As espécies de Candida foram cultivadas em meio Sabouraud líquido e após 24 h, a quantidade de células foi ajustada de acordo com a Escala de MacFarland para uma concentração de $1 \times 103$ a $5 \times 103$ células $/ \mathrm{ml}$. Os extratos foram preparados a uma concentração inicial de $4000 \mu \mathrm{g} / \mathrm{mL}$ e adicionados ao meio RPMI-MOPS. A atividade antifúngica foi avaliada através da densidade óptica, comparando a turbidez apresentada de cada cultura com o controle. 


\section{RESULTADOS E DISCUSSÃO}

A partir do preparo dos 10 extratos brutos de folhas de Inga marginata, calculou-se 0 rendimento de cada extrato, conforme a tabela 1. Os melhores rendimentos (duplicata) em ordem decrescente foram: EBIF5 (6,90 $\pm 0,30), \operatorname{EBIF} 4(5,56 \pm 0,15), \operatorname{EBIF} 2(4,19 \pm 0,10)$ e EBIF1 $(4,11 \pm 0,30)$.

Os maiores teores de polifenóis totais obtidos nos extratos estudados de EBIF, em triplicata, foram expressos em porcentagem e em ordem decrescente: EBF5 $(18,16 \pm 0,35)$; EBIF4 (16,80 \pm 0,03), EBIF3 $(12,5 \pm 1,11)$ e EBIF10 $(10,84 \pm 1,08)$, conforme tabela 1 . Com esses resultados verificou-se a importância dos três solventes, água, etanol e diclorometano na extração dos compostos fenólicos das folhas de I. marginata. Devido a sua polaridade, o maior teor de PT foi extraído com etanol e diclorometano em iguais proporções.

Tabela 1. Proporção de solvente, rendimento e teor de polifenóis totais dos extratos brutos de folhas de Inga marginata (EBIF).

\begin{tabular}{cccc}
\hline EBIF & $\begin{array}{c}\text { Extratos (Proporção de } \\
\text { solvente, \%) }\end{array}$ & Rendimento (\%) & Teor de PT (\%) \\
\hline 01 & a (100) & $4.11 \pm 0.30$ & $7.41 \pm 0.20$ \\
02 & e (100) & $4,19 \pm 0,10$ & $4,99 \pm 0,09$ \\
03 & d (100) & $0,19 \pm 0,20$ & $12,5 \pm 1,11$ \\
04 & a:e (50:50) & $5,56 \pm 0,15$ & $16,80 \pm 0,03$ \\
05 & e:d (50:50) & $6,90 \pm 0,30$ & $18,16 \pm 0,35$ \\
06 & d:a (50:50) & $2,35 \pm 0,40$ & $6,93 \pm 1,16$ \\
07 & a:e:d (33:33:33) & $3,43 \pm 0,30$ & $6,17 \pm 0,23$ \\
08 & a:e:d (68:16:16) & $3,75 \pm 0,50$ & $5,68 \pm 0,68$ \\
09 & a:e:d (16:68:16) & $3,84 \pm 0,35$ & $6,82 \pm 0,19$ \\
10 & a:e:d (16:16:68) & $1,51 \pm 0,40$ & $10,84 \pm 1,08$ \\
\hline
\end{tabular}

*a= água, e=etanol, d=diclorometano.

No ensaio de Disco-Difusão em Ágar, não se observou a presença de halos de inibição em nenhum dos extratos na concentração de $500 \mu \mathrm{g} / \mathrm{mL}$ frente aos microorganismos Staphylococcus aureus (ATCC 25923), Staphylococcus epidermidis (ATCC IE4248), Escherichia coli (ATCC 25922) e Pseudomonas aeruginosa (ATCC 27853). A difusão dos compostos no ágar depende de vários fatores, como a composição química 
e sua solubilidade no meio de cultura, sendo necessária a utilização de outros métodos complementares como microdiluição em caldo e curva de crescimento e morte.

Na curva de crescimento e morte, apenas os extratos EBIF1 (100\% água) e EBIF2 (100\% etanol), mostraram efeito antibacteriano contra S. aureus e MRSA. Após 4 h de incubação, ocorreu uma redução de $82 \%$ no número de UFC de S. aureus sob a ação do extrato etanólico (EBIF2) e no tempo de 7 h o número de UFC foi aproximadamente $150 \mathrm{X}$ e $24 \mathrm{X}$ menores do que o controle (sem extrato), sob a ação dos extratos: EBIF2 (etanólico) e EBIF1 (água), respectivamente. Para MRSA, a ação antibacteriana foi similar da cepa de S. aureus. Esses compostos demonstraram um efeito bacteriostático, uma vez que não houve redução da população bacteriana, e segundo a curva de crescimento e morte (figura 2), os compostos dos extratos dificultaram consideravelmente o crescimento bacteriano. Esses mesmos extratos (EBIF1 e EBIF2) não apresentaram efeito fungicida (CIM acima de $50 \%$ para as cepas de Candida spp). Assim, os extratos não apresentaram uma forte atividade antimicrobiana, porém, a atividade bacteriostática é um bom indício do potencial antibacteriano dos extratos de I. marginata. Futuramente, essa atividade possa ser potencializada através de novas estratégias de purificação e associação a outros compostos.

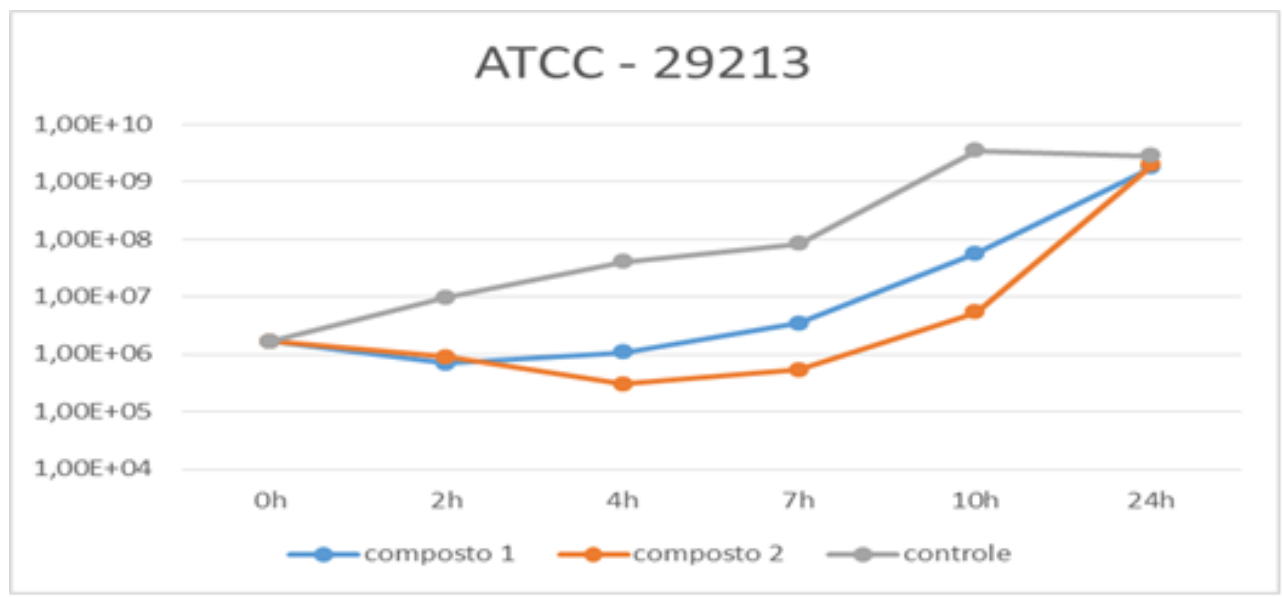

Figura 2. Curva de crescimento e morte de S. aureus (ATCC 29213) dos extratos bruto (EBIF1) e etanólico (EBIF2) de folhas de Inga marginata.

\section{CONCLUSÃO}

O estudo sugere que a eficiência de uma extração depende da proporção e da escolha dos solventes adequados, com base em suas características físico-químicas 
e dos compostos que se deseja extrair. Devido à polaridade dos solventes, houve uma extração seletiva dos compostos das amostras de folhas. O etanol e o diclorometano apresentam excelente potencial para extrair os compostos fenólicos. A análise antimicrobiana mostrou que os extratos de folhas extraídas com água e etanol apresentaram efeito bacteriostático frente aos microrganismos testados. Os resultados foram satisfatórios, pois permitiram uma melhor compreensão das propriedades das folhas de Inga marginata, sugerindo, portanto, que os extratos podem ser aplicados em formulações cosméticas com atividade antisséptica, no entanto, serão necessários estudos in vitro e in vivo.

Além disso, os resultados obtidos neste trabalho corroboram a importância dos estudos de bioprospecção envolvendo a flora regional do estado do Paraná, contribuindo para a exploração racional da biodiversidade com vistas à detecção de bioativos para o desenvolvimento de agentes terapêuticos.

\section{AGRADECIMENTOS}

A Fundação Araucária pelo auxílio financeiro, a professora Dr. leda Scarminio e a todos do Laboratório de Microbiologia Básica e de Quimiometria em Ciências Naturais da Universidade Estadual de Londrina.

\section{REFERÊNCIAS}

Álvarez, J. C., SerRanO, R. P., OSPINA, L. F.; TORRES, L. A. A. (1998). Actividad biológica de lãs saponinas de la corteza de Inga marginata Willd. Revista Colombiana de Ciências Químico-Farmacêuticas, v. 27, págs. 17-19.

BARROS NETO, B., SCARMINIO, I. S., BRUNS, R. E. (2002). Como fazer experimentos: pesquisa e desenvolvimento na ciência e na indústria. Campinas, Brasil.

CDC/NHSN. (2014). Centers for Disease Control and Prevention: Surveillance Definitions for Specific Types of Infections, Atlanta, United States.

CLSI. (2015). Performance Standards for Antimicrobial Susceptibility Testing. TwentySecond Informational Supplement. Clinical and Laboratory Standards Institute, New York, United States. 
DI STASI, L.C. (1996). Plantas medicinais: arte e ciência - um guia de estudo interdisciplinar, São Paulo, Brasil.

European Pharmacopoeia. (2007). Determination of Tannins in Herbal Drugs, sixth ed., European Directorate for the Quality of Medicines, Strasbourg, France.

GUIMARÃES, D. O., MOMESSO L. S., PUPO M. T.; Antibióticos: importância terapêutica e perspectivas para a descoberta e desenvolvimento de novos agentes. Faculdade de Ciências Farmacêuticas de Ribeirão Preto, Universidade de São Paulo, 2010.

JOLY, A.B. (1993). Botânica: introdução à taxonomia vegetal. 11. ed., São Paulo, Brasil. LIMA, N. M. (2015). BIOPROSPECÇÃO EM ESPÉCIES DE Inga (FABACEAE MIMOSOIDEAE). Tese de doutorado, Instituto de Química, Universidade Estadual Paulista, págs 23-167.

LORENZI, H. (2002). Árvores Brasileiras: Manual de Identificação e Cultivo de Plantas Arbóreas Nativas do Brasil. 2 ed. Nova Odessa, Brasil.

NYILASI, I., KOCSUBÉ, S., PESTI, M., LUKÁCS, G., PAPP, T., VÁGVÖLGYI, C. (2010). In vitro interactions between primycin and different statins in their effects against some clinically important fungi. J Med Microbiol, v. 59, págs. 200-205.

PIMENTEL, V., VIEIRA, V., MITIDIERI, T., FRANÇA, F., PIERONI, J.P. (2015). Biodiversidade brasileira como fonte da inovação farmacêutica: uma nova esperança? Revista do BNDES, v. 43, págs. 41-89

POSSETTE, R. F. S., RODRIGUES, W. A. (2010). O gênero Inga Mill. (Leguminosae Mimosoideae) no estado do Paraná, Brasil. Acta Bot. Bras, v. 24, págs. 354-368.

TRABULSI, L.R., ALTERTHUM, F. (2004). Microbiologia. 4.ed. São Paulo, Brasil. 